\title{
Experimental Research on C60 Concrete Strength Evolution under Different Curing Conditions
}

\author{
Zhu Ran ${ }^{1,2, *}$, Xu Jun ${ }^{1,2}$, Zhan Yijian ${ }^{1,2}$, Zuo Zibo ${ }^{1}$, Zhou Xiangyang ${ }^{1}$, and Shen Zhiyong ${ }^{1}$ \\ ${ }^{1}$ Shanghai Construction Group Co., Ltd, Shanghai 200080, China \\ ${ }^{2}$ Shanghai Engineering Research Center of Mega Structure High Performance Concrete
}

\begin{abstract}
An experimental study on the C60 concrete was carried out under five different curing conditions based on the maturity theory. The influence patterns of the curing conditions on the increase of the C60 concrete strength were discussed. The experimental data were fitted using different strengthmaturity models, the accuracies of which were then analyzed. The results show that the mapping relation between the compressive strength and maturity of the C60 concrete could be well characterized by the logarithmic functional relation.
\end{abstract}

\section{Introduction}

How to accurately predict the early strength of concrete has always been one of the hot issues perplexing the engineering circles. During the modern concrete construction process, the superstructure construction is fast in high-rise and super high-rise buildings, and it will take about 3-7 days to complete the construction of one storey. Only when the strength of the concrete structure on the storey reaches the design requirement can the forms and climbing framework be removed, followed by the structural construction of the next storey, or else, an engineering accident may take place. The traditional strength detection method for concrete structures may fail to scientifically reflect their strength evolution, or may need to damage their structural members, and moreover, lacking timeliness and representativeness, the traditional method could hardly satisfy the requirement for the construction period of concrete structures.

According to the research [1], the concrete strength is impacted by various factors. After the mix ratio and construction technology are determined, however, the curing temperature and age become the primary factors influencing the increase of the concrete strength. During the casting process of concrete especially mass concrete, the temperature development will generate important effects on the concrete strength evolution and structural cracks, and the compressive strength will present a growth trend with the product of temperature and time [2]. Therefore, the maturity theory is proposed to consider the influences of temperature and age on the concrete strength. This theory has been extensively applied in engineering practice as it is relatively simple and can effectively save the manpower and material resources needed in the construction process, and furthermore, its prediction accuracy for the structural strength can satisfy the engineering needs.
However, most of the strength-maturity researches [3-6] are restricted to standard indoor curing conditions, while few researches have explored the concrete strength and maturity under the outdoor curing conditions in different seasons [7]. Hence, the C60 concrete was taken the research object to carry out the experimental research and analysis under different curing conditions, expecting to reveal the influence laws of the curing conditions on the increase of the $\mathrm{C} 60$ concrete strength.

\section{Experiment}

\subsection{Experimental materials}

The experimental cement was Hailuo P.II 52.5 cement produced by Anhui Tongling Hailuo Cement Co., Ltd, and the basic physical and mechanical properties of the cement are listed in Table 1; the sand was natural river sand (medium sand) with fineness modulus of 2.69 , and the sand grading results are seen in Table 2; China Huaneng Grade II pulverized fuel ash was selected, and its physical and mechanical properties are shown in Table 3; continuously graded $(5 \sim 25 \mathrm{~mm})$ broken stones from Yangzhou were used; the water used was tap water.

\footnotetext{
* Corresponding author: zhuran@scg.cn
} 
Table 1. Basic Physical and Mechanical Properties of Cement.

\begin{tabular}{|c|c|c|c|c|c|c|c|}
\hline \multirow{2}{*}{ Fineness } & \multicolumn{2}{|c|}{ Setting time $/ \mathrm{min}$} & \multirow{2}{*}{ Soundness } & \multicolumn{2}{|c|}{ Flexural Strength/MPa } & \multicolumn{2}{|c|}{ Compressive strength/MPa } \\
\hline & Initial setting & Final setting & & $3 d$ & $28 \mathrm{~d}$ & $3 d$ & $28 \mathrm{~d}$ \\
\hline 0.4 & 127 & 173 & Qualified & 6.5 & 9.0 & 34.1 & 60.1 \\
\hline
\end{tabular}

Table 2. Sand Grading Distribution.

\begin{tabular}{cccc}
\hline Mesh size $/ \mathrm{mm}$ & Sieve residue $/ \mathrm{g}$ & Grader retained percentage $a_{\mathrm{t}} / \%$ & $\begin{array}{c}\text { Cumulative percentage } \\
\text { retained } A_{\mathrm{t}} / \%\end{array}$ \\
\hline 5.0 & 7 & 0.70 & 0.7 \\
3.15 & 30 & 3.00 & 3.70 \\
2.5 & 127 & 12.70 & 16.40 \\
1.25 & 134 & 13.40 & 29.80 \\
0.63 & 166 & 16.60 & 46.40 \\
0.315 & 169 & 17.90 & 63.40 \\
0.16 & 228 & 22.80 & 86.10 \\
$<0.16$ & 123 & 12.30 & 98.40 \\
\hline
\end{tabular}

Table 3. Physical and Chemical Properties of pulverized fuel ash.

\begin{tabular}{cccccc}
\hline & \multicolumn{3}{c}{ Table 3. Physical and Chemical Properties of pulverized fuel ash. } & \multicolumn{2}{c}{$\%$ by weight } \\
\hline \multirow{2}{*}{ Fineness } & Water demand ratio & $\begin{array}{l}\text { Loss on } \\
\text { ignition }\end{array}$ & Water content & $\mathrm{SO}_{3}$ content & Apparent density $/ \mathrm{kg} / \mathrm{m}^{3}$ \\
\hline 4.6 & 91 & 2.96 & 0.24 & 0.77 & 2240 \\
\hline
\end{tabular}

\subsection{Mix ratio design of concrete}

control the slump of the fresh mixed concrete at $180 \pm 30$ $\mathrm{mm}$. The mix ratio of the concrete is shown in Table 4 .

As the concrete used in this research was C60 pumping concrete, the water reducing agent was regulated to

Table 4. Mix Ratio of Concrete.

$\mathrm{kg} / \mathrm{m}^{3}$

\begin{tabular}{cccccccc}
\hline Cement & Water & Sand & Aggregate & Slag & Fly ash & Water reducer & Design slump \\
\hline 460 & 155 & 639 & 1003 & 64 & 53 & 5.77 & $180 \pm 30 \mathrm{~mm}$ \\
\hline
\end{tabular}

\subsection{Experimental method}

The concrete was mixed for one time using a horizontal shaft-type concrete mixer. The $100 \mathrm{~mm} \times 100 \mathrm{~mm} \times 100$ $\mathrm{mm}$ concrete cubes were used in the compressive strength test, and afterwards, the fresh mixed concretes were placed in different curing environments. The concrete specimen under the standard curing condition was firstly cured with mold in a thermostatic chamber for $24 \mathrm{~h}$ and then in a standard curing room; the

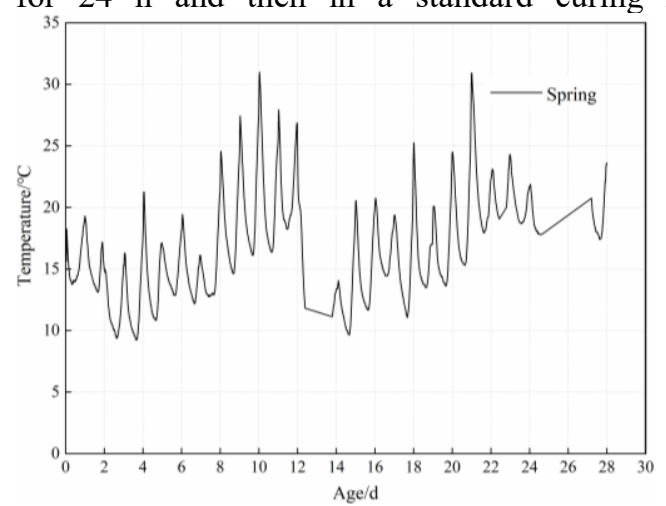

(a) Outdoor curing in spring specimen under the natural curing condition was directly cured outdoor with mold, and it was demolded $24 \mathrm{~h}$ later. In consideration of the seasonal factors during the natural curing, the compressive strength test was conducted in January, March and October, 2019, and during July-August, 2020, in an attempt to analyze the influences of the curing conditions in winter, spring, autumn and summer in Shanghai on the C60 concrete strength. The temperatures curves are seen in Fig. 1.

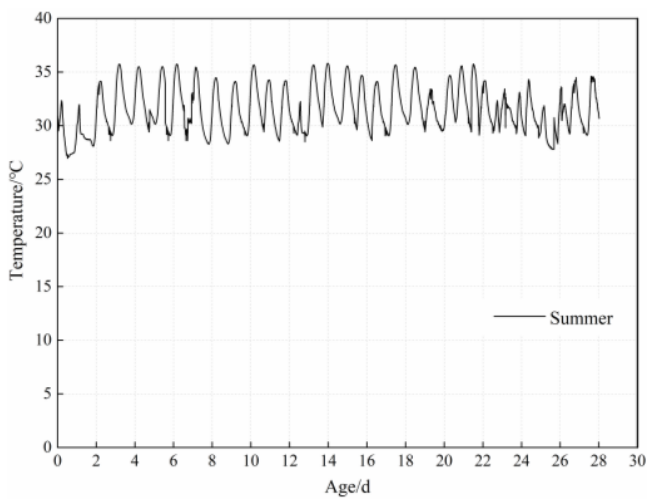

(b) Outdoor curing in summer 


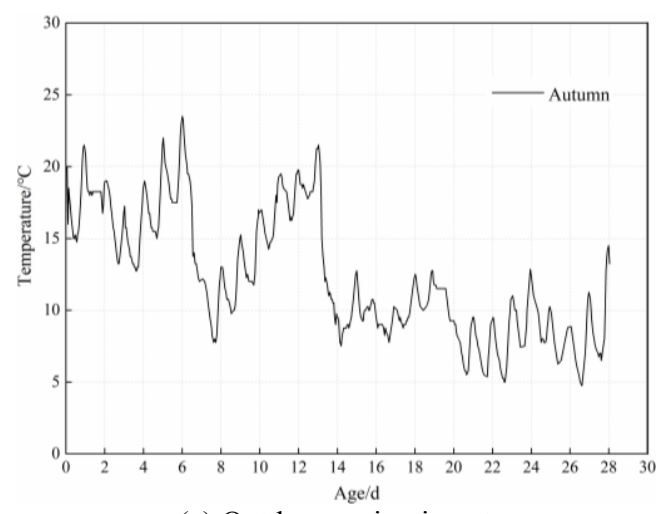

(c) Outdoor curing in autumn

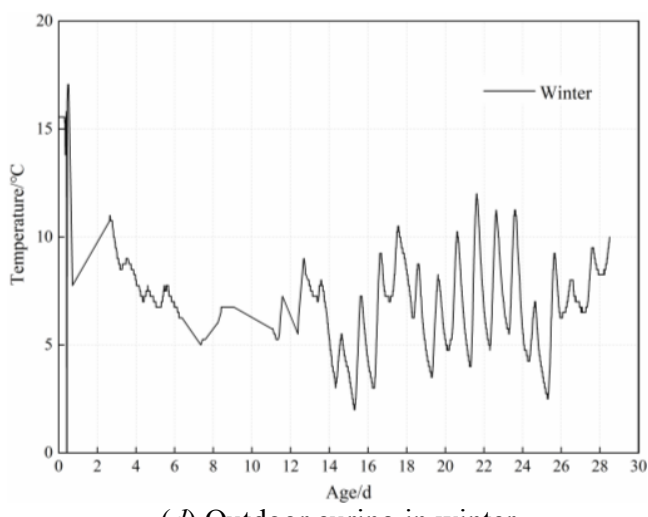

(d) Outdoor curing in winter

Fig. 1. Outdoor curing temperature curves in different seasons.

\section{Experimental Results and Analysis}

The compressive strengths of the concrete cubes under standard curing condition and those under natural curing conditions in different seasons at $1 \mathrm{~d}, 3 \mathrm{~d}, 5 \mathrm{~d}, 7 \mathrm{~d}, 14 \mathrm{~d}$ and $28 \mathrm{~d}$ were determined. The maturity values under different curing conditions at different ages were calculated using the Saul maturity calculation formula (Eq. (1)) as seen in Table 5.

$$
M=\sum_{0}^{t}\left(T-T_{0}\right) \Delta t
$$

where $M$ is maturity $\left({ }^{\circ} \mathrm{C} \cdot \mathrm{h}\right.$ or $\left.{ }^{\circ} \mathrm{C} \cdot \mathrm{d}\right) ; T$ is average concrete temperature $\left({ }^{\circ} \mathrm{C}\right)$ within the time interval $\triangle t ; T_{0}$ is the reference temperature $\left({ }^{\circ} \mathrm{C}\right)$ at which the concrete strength will not increase with the age, namely, the temperature at which the hydration reaction inside the concrete stops, and it is generally taken as $-10^{\circ} \mathrm{C} ; \Delta t$ is time interval ( $\mathrm{h}$ or d).

Table 5. Calculation Results of Compressive Strength and Maturity of Concrete.

\begin{tabular}{|c|c|c|c|c|c|c|c|}
\hline Curing condition & Age/d & 1 & 3 & 5 & 7 & 14 & 28 \\
\hline \multirow{2}{*}{ Standard curing at $20^{\circ} \mathrm{C}$} & Maturity $/{ }^{\circ} \mathrm{C} \cdot \mathrm{h}$ & 720 & 2160 & 3600 & 5040 & 10080 & 20160 \\
\hline & $\mathrm{C} 60 / \mathrm{MPa}$ & 21.9 & 47.2 & 52.0 & 54.5 & 58.4 & 61.1 \\
\hline \multirow{2}{*}{ Outdoor curing in spring } & Maturity $/{ }^{\circ} \mathrm{C} \cdot \mathrm{h}$ & 612.3 & 1734.6 & 2843.9 & 4029.8 & 8625.1 & 17980.4 \\
\hline & $\mathrm{C} 60 / \mathrm{MPa}$ & 19.4 & 42.8 & 45.9 & 47.3 & 54.8 & 59.4 \\
\hline \multirow{2}{*}{ Outdoor curing in summer } & Maturity $/{ }^{\circ} \mathrm{C} \cdot \mathrm{h}$ & 929.6 & 2860.9 & 4898.9 & 6916.7 & 13910.7 & 27938.7 \\
\hline & $\mathrm{C} 60 / \mathrm{MPa}$ & 40.0 & 54.4 & 56.4 & 57.2 & 59.5 & 62.5 \\
\hline \multirow{2}{*}{ Outdoor curing in autumn } & Maturity $/{ }^{\circ} \mathrm{C} \cdot \mathrm{h}$ & 657.8 & 1963.2 & 3202.8 & 4546.7 & 8654.9 & 15027.3 \\
\hline & $\mathrm{C} 60 / \mathrm{MPa}$ & 20.9 & 46.1 & 48.6 & 51.4 & 56.9 & 58.4 \\
\hline \multirow{2}{*}{ Outdoor curing in winter } & Maturity $/{ }^{\circ} \mathrm{C} \cdot \mathrm{h}$ & 539.7 & 1481.2 & 2346.4 & 3144.2 & 5898.8 & 11468.3 \\
\hline & $\mathrm{C} 60 / \mathrm{MPa}$ & 12.6 & 32.7 & 39.5 & 43.2 & 48.7 & 51.3 \\
\hline
\end{tabular}

From Table 5, the curing temperature has a great bearing on the compressive strength of concrete. The concrete strength under the curing condition in winter was lower than those under other curing temperatures at all ages, indicating that the outdoor continuous low temperature in winter would generate an adverse effect on the increase of the concrete strength, and this effect was more obvious at early age. Nevertheless, this adverse effect would be gradually weakened with the concrete age. Given this, the effect of the curing temperature on the concrete strength at early age was stronger than that at later age. The increase of the concrete strength mainly depended upon the cement hydration. In comparison with the standard curing environment at $20^{\circ} \mathrm{C}$, the chemical reaction rate of the concrete was naturally lowered under low-temperature condition in winter, which resulted in the reduction of the cement hydration rate and hydration degree, and further slowed down the increase of the concrete strength.

The concrete strength under the curing condition in summer was significantly lower than those under other curing conditions before $7 \mathrm{~d}$, but the later strength in summer was slightly higher than that under the indoor curing condition and those under the curing conditions in spring and autumn. To figure out why, the hydration reaction inside the concrete was accelerated due to the rise of curing temperature, the concrete strength was then improved, but the hot arid conditions in summer led to the moisture evaporation and loss inside the concrete, thus impacting the continuous cement hydration. Spears [8] deemed that the cement hydration reaction would tend to stop when the relative humidity inside the concrete was smaller than $80 \%$; meanwhile, the tensile stress was generated in the concrete due to shrinkage, and consequently, the cracks were generated on the concrete surface and its strength was degraded.

The maturity index can indirectly reflect the change of the concrete performance. As pointed out by Carino [9], certain mapping relations exist between the concrete strength and maturity, and the 3 classical relations are 
presented in Table 6 .

In order to obtain the relation between the concrete strength and maturity, the 3 models in Table 6 were respectively fitted. The deviations of the predicted strength from the measured strength are displayed in Fig. 2 .

Table 6. Strength-Maturity Relation [9].

\begin{tabular}{lcl}
\hline Model form & Functional relation & \multicolumn{1}{c}{ Remark } \\
\hline Logarithmic & $f=a+b \log (M)$ & $f$ is concrete strength; \\
Exponential & $f=a e^{-b / M}$ & $\begin{array}{l}M \text { is maturity; } a \text { and } \\
b \text { are regression }\end{array}$ \\
Hyperbolic & $f=M /(a M+b)$ & constants.
\end{tabular}

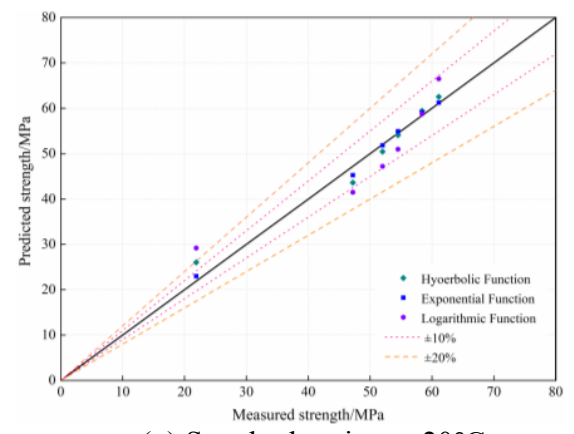

(a) Standard curing at $20^{\circ} \mathrm{C}$

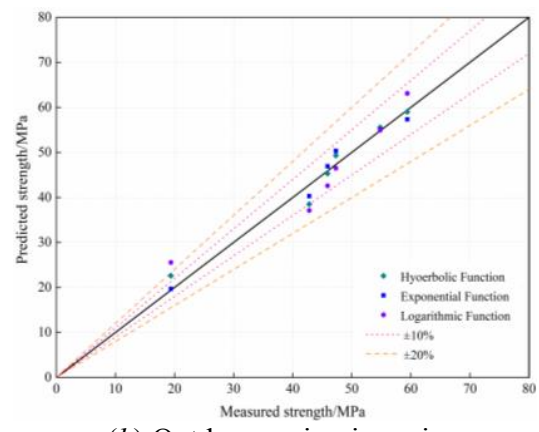

(b) Outdoor curing in spring

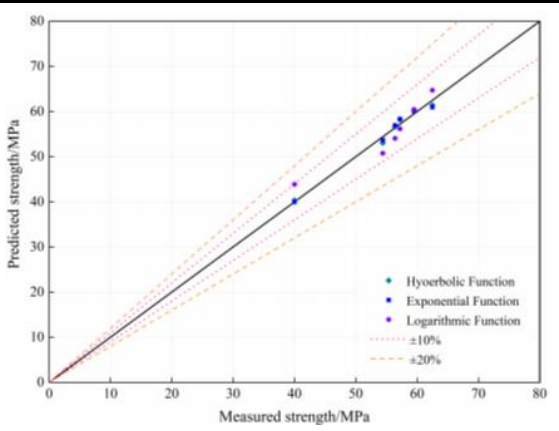

(c) Outdoor curing in summer

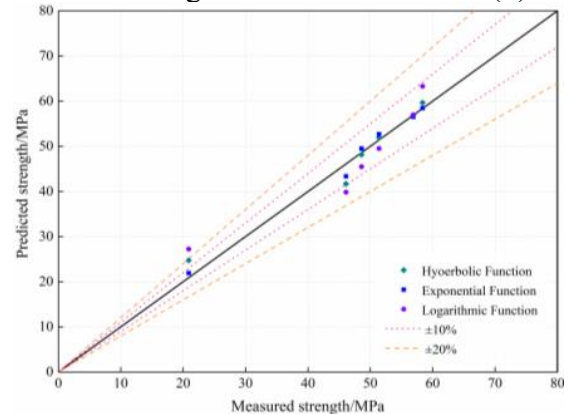

(d) Outdoor curing in autumnn

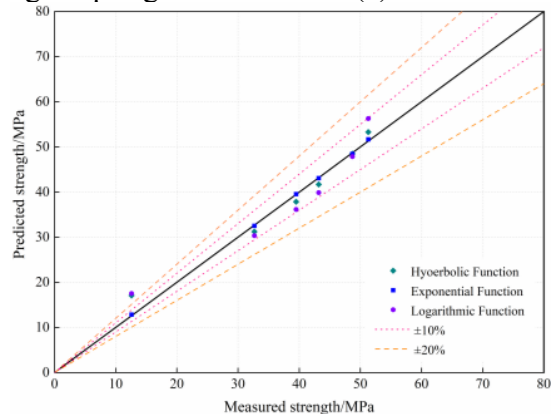

(e) Outdoor curing in winter

Fig. 2. Measured strength-predicted strength relations at the same maturity under different curing conditions.

As shown in Fig. 2, the range of prediction deviation was within $\pm 10 \%$ when the exponential model was used

Table 7. Model Parameter Fitting Results under Different Curing Conditions.

\begin{tabular}{ccc}
\hline Curing condition & Fitting parameter & Value \\
\hline Standard curing at $20^{\circ} \mathrm{C}$ & $a$ & 63.52 \\
Outdoor curing in spring & $b$ & 732.3 \\
& $R^{2}$ & 0.9944 \\
Outdoor curing in summer & $a$ & 59.55 \\
& $R^{2}$ & 678.1 \\
& $a$ & 0.9784 \\
Outdoor curing in autumn & $b$ & 61.87 \\
& $R^{2}$ & 406.4 \\
& $a$ & 0.9806 \\
& $b$ & 61.14 \\
Outdoor curing in winter & $R^{2}$ & 675.1 \\
& $a$ & 0.9879 \\
& $b$ & 55.36 \\
\hline
\end{tabular}

to predict the concrete strengths at different curing temperatures and different ages; when the exponential model was adopted, the range of prediction deviation exceeded $10 \%$ and even exceeded $20 \%$ before $7 d$; when the early strength was predicted using the hyperbolic model, the prediction accuracy was between the exponential form and logarithmic form. Therefore, the exponential form is suitable for predicting the C60 concrete strength in this experiment, and the fitting parameters are seen in Table 7.

\section{Conclusion}

The mapping relations between the C60 concrete strength and maturity were experimentally investigated under different curing conditions, and the results manifest that:

1) The concrete strength is in direct proportion to the curing temperature. To be specific, the higher the curing temperature, the stronger its compressive strength (especially early strength) will be;

2) The concrete strength is influenced by the humidity. The increase of the concrete strength will be repressed in a high-temperature and low-humidity environment. Hence, special attention should be paid to moisture curing during the outdoor concrete pouring process in summer; 
3) In comparison with the logarithmic function and hyperbolic function, the exponential function can more accurately characterize the mapping relations between the compressive strength and maturity of the concrete under different curing conditions. This can provide a technical reference for the construction of concrete structures.

\section{Acknowledgments}

This research was financially supported by the National Key R\&D Program of China (Project No. 2017YFC0703700), the Shanghai Committee of Science and Technology (No. 18DZ2282600) and Shanghai Construction Group Co., Ltd (Project No. 17YJKF-13).

\section{References}

1. Saul A. (1951) Principles underlying the steam curing of concrete at atmospheric pressure. Magazine of Concrete Research, 2(6): 127-140.

2. Nurse R. (1949) Steam curing of concrete. Magazine of Concrete Research, 1(2): 79-88.

3. Carino N.J., Lew H., Volz C.K. (1983) Early age temperature effects on concrete strength prediction by the maturity method. ACI Material Journal. 80(2): 93-101.

4. Kim T. (2004) Concrete maturity: A quantitative understanding of how early-age temperature affects the maturity concept. Boulder: University of Colorado.

5. Volz C.K., Tucker R.L., Burns N.H., et al. (1981) Maturity effects on concrete strength. Cement and Concrete Research, 11(1): 41-50.

6. Plowman J. (1956) Maturity and the Strength of Concrete. Magazine of Concrete Research, 8(22): 13-22.

7. Ge Z. (2005) Predicting temperature and strength development of the field concrete. Ames: Iowa State University.

8. Spears R.E. (1983) The 80 percent solution to inadequate curing problems. Concrete international, 5(4): 15-18.

9. Carino N.J. (1984) The maturity method: theory and application. Cement, concrete and aggregates, 6(2): 61-73. 